OPEN ACCESS

Edited by:

Luis Henrique Braga,

McMaster University, Canada

Reviewed by:

Ali Avanoglu,

Ege University, Turkey

Armando J. Lorenzo,

Hospital for Sick Children, Canada

*Correspondence:

Andrew J. Kirsch akirschmd@gmail.com

Specialty section: This article was submitted to

Pediatric Urology,

a section of the journal

Frontiers in Pediatrics

Received: 06 January 2021 Accepted: 05 March 2021 Published: 31 March 2021

Citation:

Läckgren G, Cooper CS, Neveus T and Kirsch AJ (2021) Management of Vesicoureteral Reflux: What Have We

Learned Over the Last 20 Years?

Front. Pediatr. 9:650326

doi: 10.3389/fped.2021.650326

\section{Management of Vesicoureteral Reflux: What Have We Learned Over the Last 20 Years?}

\author{
Göran Läckgren ${ }^{1}$, Christopher S. Cooper ${ }^{2}$, Tryggve Neveus ${ }^{3}$ and Andrew J. Kirsch ${ }^{4 *}$ \\ ${ }^{1}$ Section of Urology, Department of Pediatric Surgery, University Children's Hospital, Uppsala, Sweden, ${ }^{2}$ Department of \\ Urology, University of lowa, lowa City, IA, United States, ${ }^{3}$ Department of Women's and Children's Health, Uppsala University, \\ Uppsala, Sweden, ${ }^{4}$ Pediatric Urology, Children's Healthcare of Atlanta and Emory University School of Medicine, Atlanta, \\ GA, United States
}

Vesicoureteral reflux (VUR) is associated with increased risks of urinary tract infection, renal scarring and reflux nephropathy. We review advancements over the last two decades in our understanding and management of VUR. Over time, the condition may resolve spontaneously but it can persist for many years and bladder/bowel dysfunction is often involved. Some factors that increase the likelihood of persistence (e.g., high grade) also increase the risk of renal scarring. Voiding cystourethrography (VCUG) is generally considered the definitive method for diagnosing VUR, and helpful in determining the need for treatment. However, this procedure causes distress and radiation exposure. Therefore, strategies to reduce clinicians' reliance upon VCUG (e.g., after a VUR treatment procedure) have been developed. There are several options for managing patients with VUR. Observation is suitable only for patients at low risk of renal injury. Antibiotic prophylaxis can reduce the incidence of UTIs, but drawbacks such as antibiotic resistance and incomplete adherence mean that this option is not viable for long-term use. Long-term studies of endoscopic injection have helped us understand factors influencing use and the effectiveness of this procedure. Ureteral reimplantation is still performed commonly, and robot-assisted laparoscopic methods are gaining popularity. Over the last 20 years, there has been a shift toward more conservative management of VUR with an individualized, risk-based approach. For continued treatment improvement, better identification of children at risk of renal scarring, robust evidence regarding the available interventions, and an improved VUR grading system are needed.

Keywords: antibiotic, bladder/bowel dysfunction, endoscopic injection, NASHA/Dx, vesicoureteral reflux, ureteral reimplantation, urinary tract infection, voiding cystourethrogram

\section{INTRODUCTION}

Vesicoureteral reflux (VUR) is associated with increased risks of urinary tract infection and renal scarring or reflux nephropathy (1). Reflux nephropathy in children with VUR may be attributable to scars from upper urinary tract infection (UTI) as well as congenital renal dysplasia (1). The severity of VUR is described by a grading system according to the findings of a voiding cystourethrogram (VCUG), with grades ranging from I (mild) to V (severe). In most cases, VUR does not directly cause any symptoms; it is diagnosed either antenatally in children with hydronephrosis, or later following the occurrence of symptomatic UTIs $(2,3)$. Diagnosing the condition can be challenging 
due to the lack of direct symptoms and, in neonates and young infants, this is compounded by the non-specific manner with which UTIs present. Estimated prevalence rates for VUR range between 0.4 and $1.8 \%(4,5)$.

Numerous studies have examined the links between VUR, UTIs, pyelonephritis, renal scarring and impaired renal function. In a study of 115 infants with grade III-V reflux, single-kidney glomerular filtration rate (GFR) was below $40 \%$ of the individual's total expected value in $71 \%$ of the patients, and a deterioration in renal status was observed in $18 \%$ of the patients (6). Recurrent febrile UTIs (fUTIs), bilateral renal abnormalities and reduced total GFR were identified as risk factors for renal deterioration. Swerkersson et al. evaluated VUR and renal scarring in children aged $<2$ years presenting with UTI (7). VUR and renal scarring were each present in $26 \%$ of the study participants, and the rate of renal abnormality increased significantly with increasing grade of VUR. A later study by the same group assessed changes over time in children aged $<2$ years presenting with UTI who were found to have renal scarring (8). Over a follow-up time of at least 2 years, $19 \%$ of the children exhibited renal deterioration. Grade III-V VUR and recurrent UTI were identified as risk factors for deterioration. Hidas et al. developed an instrument for predicting the risk of breakthrough UTI in children with VUR (9). VUR grade, gender, circumcision status, presence of bladder/bowel dysfunction (BBD) and cause of presentation of VUR enabled stratification of children into different risk groups. When the instrument was applied to a validation cohort, the predicted 2year incidence of breakthrough UTI was 19.5\%, compared with an actual rate of $21 \%(9)$. Arlen et al. similarly developed a tool for calculating the risk of a breakthrough fUTI in children with VUR based on risk factors for UTIs [including age, gender, VUR grade, reflux at low bladder volume, bladder/bowel dysfunction (BBD) and UTI history] (10). In a cohort of 255 children, the calculator was shown to have $76 \%$ accuracy. A study by Keren et al. investigated risk factors for recurrent UTI and renal scarring in children aged 2-71 months who had experienced one or two febrile or symptomatic UTIs (11). VUR, BBD and renal scarring were all associated with increased likelihood of recurrent UTIs. In males, circumcisional status may also be an important risk factor for UTI. One review reported that circumcision is associated with an $87 \%$ reduction in the incidence of UTI among boys with high-grade VUR (12).

In a Turkish study of 156 children aged $0-16$ years with UTIs, increasing grade of VUR was associated with increasing rates of renal scarring (13). A longitudinal study with median followup of 5.6 years was conducted to investigate the association between renal scarring and adverse renal outcomes in children with a diagnosis of UTI or VUR (14). Patients with, vs. without, renal scarring showed significantly increased risk of developing proteinuria (5.1 vs. $1.6 \%, p=0.005)$ and kidney disease $(2.0$ vs. $0.0 \%, p=0.005)$. The available data support intervention in patients with VUR to reduce the risks of pyelonephritis and renal scarring, which can have permanent consequences.

VUR has long been known to resolve spontaneously over time. However, a decision to wait for this to occur rather than treating or curing the condition should only be taken in the absence of repeat fUTIs that could cause renal scarring. In 1998,
Wennerström et al. reported that grade III-V reflux resolved spontaneously (to grade $0-\mathrm{I}$ ) in $73 \%$ of cases over a follow-up period of 10 years (15). Early investigations also showed that older age, high-grade VUR and female gender were associated with a lower likelihood of spontaneous VUR resolution $(15,16)$. Later studies identified high-grade VUR, renal abnormalities, prenatal hydronephrosis, bladder dysfunction, low bladder filling volume at reflux onset, breakthrough UTI and older age upon diagnosis of VUR as independent predictors of a lower likelihood of spontaneous resolution (17-21). Evidence suggests that effective treatment of $\mathrm{BBD}$ can increase the chance of spontaneous resolution of VUR (22). Kirsch et al. performed multivariate analysis on outcomes from 229 patients diagnosed with VUR before the age of 2 years, and reported that patients with the following had significantly longer time to spontaneous resolution: grade IV-V VUR, duplicated ureters or periureteral diverticula, occurrence of reflux during bladder filling, and female gender (23). The occurrence of reflux early during bladder filling has been associated with low spontaneous resolution rates and increased risk of fUTI, independent of the grade of VUR $(18,23,24)$.

VUR and BBD are closely related and around half of patients with VUR also have BBD (25). Among patients with VUR, additional presence of $\mathrm{BBD}$ approximately doubles the risk of UTIs $(11,25,26)$. As mentioned above, co-existent BBD may also reduce the likelihood of spontaneous resolution of VUR, and BBD has been associated with reduced success in patients undergoing endoscopic injection for VUR $(17,27)$. On the other hand, intervention for VUR can lead to the improvement or cure of $\mathrm{BBD}$, indicating a degree of interdependence between the two conditions (28-30). Treatment of BBD as well as VUR in patients with both conditions appears to be advisable $(22,27)$.

In females, VUR is associated with increased risk of pregnancy-related complications such as pre-eclampsia and UTI $(31,32)$. This is mainly attributable to the presence of renal scarring, supporting the notion that preventing renal damage should be a key goal of VUR management. However, UTI prevention may also be important since the risk of fetal complications is elevated among women with frequent UTIs (32).

There are four main options for managing patients with VUR: observation, antibiotic prophylaxis, endoscopic injection and ureteral reimplantation (33-35).

\section{DIAGNOSIS AND ASSESSMENT}

The key aims of assessment are to determine how and when the patient should undergo treatment. VCUG has been described as the only definitive method of diagnosing VUR and defining its severity (36-38). However, inter-rater variability is common with this assessment. Some studies have reported favorable intraclass correlation coefficient (ICC) values between 0.8 and 0.9 , but lower levels of inter-rater agreement $(50-60 \%)$ have also been reported (39-42). To improve the reliability of results, a standardized protocol should be adhered to when performing this assessment $(37,43)$. Specifications such as choice of contrast, method for infusing contrast, timing and quality of spot images, 
and documentation of bladder volume at onset of VUR ensure consistency (37). Also, more than one cycle of filling and voiding may be needed to avoid the possibility of underdiagnosing VUR (44). Optimal VCUG methodology is not always followed, and this represents an opportunity to improve routine clinical practice (43).

Perceived importance of the available assessments of VUR patients has changed significantly over the last 20 years. Historically, the grade of VUR was often the only determinant of treatment decisions. The VCUG procedure causes considerable distress and exposes patients to radiation. Strategies to reduce clinicians' reliance upon VCUG have therefore been developed (45). As well as the grade of VUR, treatment decisions are routinely based on age, gender, UTI occurrence and the presence of renal scarring. Determination if the patient has $\mathrm{BBD}$ is particularly important. Reproducible, validated methods for diagnosing BBD are limited and an 18-item questionnaire developed in 2019 was shown to enable reliable diagnosis and subcategory classification (46). VCUG assessment is considered necessary in patients with recurrent fUTIs $(38,47,48)$. For children aged 2-24 months presenting with their first fUTI, routine VCUG is supported by the American Academy of Pediatrics only if there is an abnormality on a renal and bladder ultrasound scan $(36,49)$. Assessments other than VCUG that can help determine appropriate therapies include the frequency of UTIs or fUTIs, renal function tests [e.g., dimercaptosuccinic acid (DMSA) or mercaptoacetyltriglycine (MAG-3) scanning], ultrasound scanning, and assessment of bowel and bladder function (49-54).

A future shift toward assessing the severity of VUR in patients with methods that are more objective and easily measurable than the current grading system is recommended by the authors. The distal ureteral diameter ratio (UDR; diameter of distal ureter normalized to the L1-L3 vertebral body distance; measurable using VCUG images) has been shown to be predictive of spontaneous resolution of VUR and risk of breakthrough fUTI (55-58). Each unit increase of UDR of 0.1 is associated with a significant increase in the probability of VUR persistence $(55,56,59)$. A significant decrease in inter-grader variability has been reported with the UDR assessment compared with VUR grading, with ICC values of 0.95 and 0.87 , respectively (59). Knowledge of the factors involved in spontaneous resolution of VUR prompted the development of computational prediction methods (60). Subsequently, a VUR index was proposed, where a patient's clinical characteristics (e.g., gender, grade of VUR, timing of VUR) are used to predict the likelihood of spontaneous resolution (23). Reliability of this index was initially shown in a cohort of VUR patients aged $<2$ years $(n=229)$, and then validated in a second cohort of patients aged $<2$ years $(n=$ $369)$ as well as in 271 patients aged $>2$ years $(23,61,62)$. The VUR index score has also been shown to correlate with the risk of developing UTIs (Figure 1) $(23,62,63)$. Importantly, both UDR and VUR index appear superior to international VUR grading in predicting either spontaneous resolution of VUR or risk of a breakthrough UTI in children aged $<2$ years at diagnosis $(55,61,63)$. Contrast-enhanced voiding urosonography (ceVUS) could potentially be used as a replacement for VCUG. This

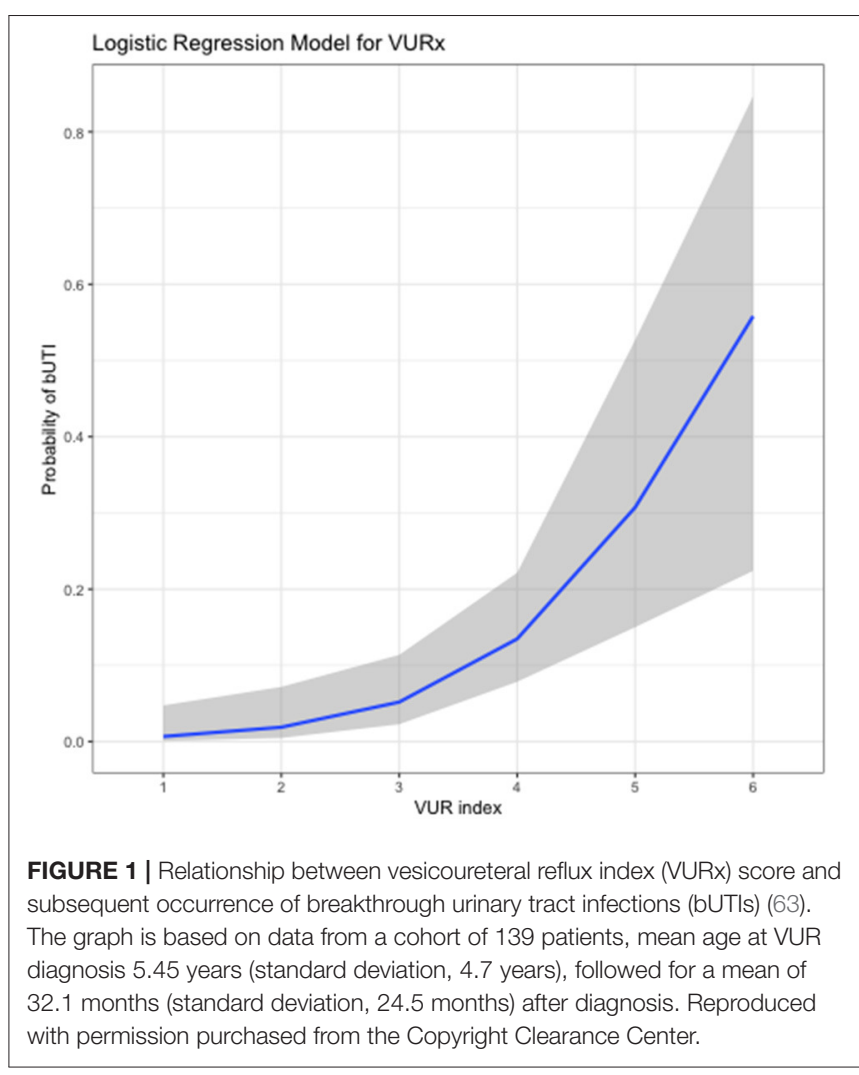

method enables determination of the presence and grade of VUR in a similar manner to VCUG, without exposing the patient to ionizing radiation. Available evidence suggests that ceVUS may provide acceptable diagnostic accuracy (64-66). In one study using VCUG results as the reference point, ceVUS was shown to provide sensitivity of $92 \%$ and specificity of $98 \%$ (65). The concordance rate between the two methods in determining the grade of VUR was $82 \%$. Further data are needed to establish the suitability of ceVUS for use in routine clinical practice.

\section{TREATMENT APPROACHES}

The principal aim of VUR management is to reduce kidney infections and renal scarring. In addition, clinicians should aim to prevent UTIs and minimize long-term assessment and treatment procedures. Management may be non-surgical (e.g., urotherapy, antibiotic therapy), minimally invasive (endoscopic injection) or surgical (ureteral reimplantation), and these approaches are detailed below.

\section{Observation}

The selection of "observation" may be perceived as favorable due to the avoidance of medical intervention. However, regular follow-up visits to the clinic are required to enable adequate monitoring of the patient's status. In addition, parents must always be vigilant to ensure that all UTIs are reported and managed. Antibiotic therapy should be administered promptly to treat fUTIs, while frequent occurrence of UTIs is an indication for a different management strategy $(1,22,67)$. Observation is 
only considered suitable for patients with a relatively low risk of renal injury (i.e., males with low-grade VUR) (68-70).

\section{Antibiotic Prophylaxis}

Antibiotic prophylaxis has been reported to be effective in preventing UTIs. In the randomized intervention for children with vesicoureteral reflux (RIVUR) trial, the risk of recurrent infection was reduced by $50 \%$ vs. placebo among VUR patients with one or two prior UTIs (71). Similarly, in the randomized Swedish Reflux study which compared antibiotic prophylaxis with endoscopic injection and observation in children with VUR, the incidence of recurrent fUTIs was significantly lower in girls receiving antibiotic prophylaxis vs. observation (19 vs. $57 \%$ over a median period of 2 years; $p=0.0002$ ) (72). In boys, the numbers of recurrent fUTIs were low in both study groups, with no significant difference. The RIVUR trial and others have demonstrated that delayed treatment of UTIs increases the risk of renal scarring $(71,73,74)$. Despite the data showing possible benefits of antibiotic treatment, it is important to consider that VUR often persists for years, meaning that antibiotic prophylaxis is often needed for a prolonged duration. In contradiction to the studies above, a 2019 Cochrane review reported that longterm antibiotic prophylaxis "makes little or no difference to the risk of repeat UTI causing a person to be unwell" (34). Other studies also suggest that prophylactic antibiotic therapy can often be discontinued without incurring significantly increased UTI rates (75). The extent to which patients adhere to their prescribed treatment may explain some of the variability between studies, with real-world compliance rates tending to be considerably lower than those in clinical trials. In 2007, Hensle et al. reported a compliance rate of only $17 \%$, suggesting widespread exposure to the same risk of UTIs as children under observation only (76).

The risk of antibiotic resistance in children receiving prophylactic antibiotics is an important consideration when choosing between management options $(34,71,77,78)$. Another possible drawback of antibiotic prophylaxis is deleterious effects on the microbiome of the gut, which can have a significant impact on patients' overall health $(77,79-81)$. These aspects are now recognized to a much greater extent than they were 20 years ago.

A cost-effectiveness analysis of antibiotic therapy was performed using results from the RIVUR trial (82). This study showed that antibiotic prophylaxis has marginally higher costs than placebo, while significantly reducing the incidence of infection. A second cost-utility analysis reported that antibiotic prophylaxis is only cost-effective if administered to patients with grade IV VUR; costs per quality-adjusted life-year gained in patients with grade I-III VUR were deemed prohibitively high (83).

In the future, it may become possible to better select specific patients who would benefit from antibiotic prophylaxis (84). However, the viability of long-term antibiotic prophylaxis as a treatment option for all patients with VUR remains questionable.

\section{Endoscopic Injection}

Clinical data from numerous studies have confirmed longterm safety and efficacy of endoscopic injection. In a metaanalysis published in 2016, the overall resolution rate ranged between 71 and $83 \%$, depending on the injection technique. Studies with long-term follow-up [3-22 years, mostly performed with NASHA/Dx (Deflux)] have similarly reported resolution rates ranging between 69 and 100\% (28, 85-88). In addition to results in "uncomplicated" VUR, numerous studies have provided evidence that endoscopic injection is also effective in specific patient populations that may be deemed more difficult to treat (historically not considered for endoscopic therapy). These include high-grade VUR, duplicated systems, adult women and kidney transplant patients $(85,86,89-104)$. Resolution rates may be reduced in these groups of patients: for example, Läckgren et al. reported a positive response rate of $63 \%$ in patients with duplicated ureters, compared with $68 \%$ in the broader population of VUR patients $(104,105)$. However, the success rates are high enough for endoscopic injection to remain viable in these groups of patients.

A range of factors have been shown to influence the resolution rate with endoscopic injection. Statistically significant effects on outcomes have been reported with VUR grade, injection technique, physician experience, patient age, and the extent of renal scarring at time of treatment (35, 106-108). In addition, high UDR values have been associated with reduced likelihood of VUR resolution following endoscopic injection (109). Baydilli et al. recently studied associations between a range of clinical parameters and the outcome of endoscopic therapy with NASHA/Dx (110). The factors associated with greatest increase in the likelihood of failure of NASHA/Dx to resolve VUR were: onset of reflux during the early filling phase of the voiding cycle, UDR value above 0.24 , and a delay in upper urinary tract drainage after voiding. Presence of renal scarring, presence of $\mathrm{BBD}$, history of fUTI and high-grade VUR were also associated with significantly increased risk of treatment failure.

There is little evidence of major differences in VUR resolution rates between injectable agents in current use (34). This appears contingent upon formation of a longlasting bolus following injection; experience with bovine collagen indicated lower efficacy than with other injectable agents (111-113). This was attributable to degradation of collagen post-injection, and collagen is not currently used for endoscopic treatment of VUR. The choice of injectable agent may have a more significant impact on the safety of endoscopic injection. Early investigations of endoscopic injection were performed using polytetrafluoroethylene (PTFE) and polydimethylsiloxane (silicone). Safety concerns with these products include granuloma formation (a foreign-body reaction), migration from the injection site, and, because of their lack of biodegradability, permanent accumulation within the body (113-115). These considerations led to PTFE and silicone falling out of common use in patients with VUR.

Recently developed injectable agents include polyacrylatepolyalcohol copolymer, polyacrylamide hydrogel, and small-size $(80-120 \mu \mathrm{m})$ dextranomer/hyaluronic acid copolymer (116). Like PTFE and silicone, polyacrylate-polyalcohol copolymer and polyacrylamide hydrogel are non-biodegradable, meaning they can remain within the body permanently. They both have a favorable histopathologic profile, but foreign-body reactions are possible (117-120). Polyacrylate-polyalcohol 
copolymer has been associated with risks of periureteral fibrosis (potentially complicating subsequent ureteral reimplantation) and obstruction of the vesicoureteral junction $(116,121)$. Comparative studies suggest that polyacrylatepolyalcohol copolymer, polyacrylamide hydrogel and small-size dextranomer/hyaluronic acid copolymer are at least as effective as NASHA/Dx in resolving VUR $(106,121-124)$. Only one of these studies was a prospective, randomized trial; the results showed comparable efficacy with NASHA/Dx and polyacrylatepolyalcohol copolymer (121). The only other prospective study (non-randomized) also reported similarity between the two agents being compared (NASHA/Dx and polyacrylamide hydrogel) (123). The remaining comparisons of recently developed materials vs. NASHA/Dx were retrospective, limiting the robustness of the results. Small-size dextranomer/hyaluronic acid copolymer (brand names Urodex, Vurdex and Dexell) differs from NASHA/Dx (brand name Deflux) not only in the size of the dextranomer microspheres, but also in the characteristics of the hyaluronic acid, potentially affecting the safety profile, physical properties and ease/controllability of the injection procedure. Importantly, these differences mean that clinical results obtained with NASHA/Dx are not directly applicable to small-size dextranomer/hyaluronic acid copolymer. Long-term efficacy and safety data ( $>5$ years) are yet to be published with any of the recently developed agents. We advocate NASHA/Dx because of its long-term safety (documented follow-up to 25 years), robust published evidence of efficacy and international regulatory approval (in the USA, it is the only FDA-approved material for endoscopic treatment of VUR).

A limited number of studies have assessed the pharmacoeconomics of endoscopic treatment of VUR. Early data published by Kobelt et al. in 2003 showed that, in the USA, endoscopic treatment with NASHA/Dx could reduce the cost of VUR management without reducing the clinical success rate (125). Another US study, published 3 years later, similarly reported that NASHA/Dx could be more cost-effective than ureteral reimplantation in patients with unilateral grade III VUR, although not in patients with bilateral grade III VUR or grade IV-V VUR, in whom larger volumes of NASHA/Dx are needed (126). In 2008, total reimbursement costs in the USA were found to be lower with outpatient ureteral reimplantation than with endoscopic injection for VUR (127). However, the cost difference was only $\sim 10 \%$, and total reimbursement for ureteral reimplantation was increased if a proportion of these patients require hospital admission. In 2016, results from patients treated in two European centers were analyzed to compare endoscopic treatment of VUR using NASHA/Dx with two methods of ureteral reimplantation (open Cohen and laparoscopic Lich-Gregoir) (128). Intra-operative costs were highest with endoscopic injection, but the total cost (intra-operative plus post-operative hospitalization costs) was highest with the Cohen procedure (€8201), and similar with endoscopic treatment and laparoscopic reimplantation (€3283 and €3211, respectively). Observations regarding lower product costs with polyacrylamide hydrogel and smallsize dextranomer/hyaluronic acid copolymer vs. NASHA/Dx have been made in some publications $(88,123,129)$. Simple comparisons of product costs do not provide a complete pharmacoeconomic picture: formal studies that include the total long-term costs of patient management (influenced by long-term safety and efficacy of the treatments concerned) are needed for true pharmacoeconomic comparisons.

\section{Ureteral Reimplantation}

Ureteral reimplantation is associated with high resolution rates $(>90 \%)$ in grade $\leq \mathrm{IV}$ VUR. It is considered an invasive procedure that requires hospital admission and time for recovery (130-134). There is a small risk of post-operative complications; these occur in $\sim 5-9 \%$ of children undergoing open surgery $(134,135)$.

Laparoscopic and robotic methods have the potential to reduce the invasiveness of ureteral reimplantation, and these methods are gaining popularity (136). A multicenter, retrospective analysis of laparoscopic ureteral reimplantation conducted in patients with grade II-IV VUR reported a success rate of 96\% (137). A 2016 review of laparoscopic ureteral reimplantation also reported a median success rate of $96 \%$, with a complication rate of $7 \%$ (138). Success rates similar to those with open surgery ( $>90 \%$ ) have been reported with robot-assisted laparoscopic ureteral reimplantation, although there is evidence that the success rate with this method may be lower (around 80\%) when the procedure is performed bilaterally (139-141). Urinary retention has been reported as a complication among patients undergoing robot-assisted ureteral reimplantation, and the overall complication rate appears higher in patients undergoing bilateral procedures $(140,142)$. The costeffectiveness of robot-assisted ureteral reimplantation has been questioned due to higher costs and higher complication rates compared with open surgery (135). The learning curve for robotic surgery can be substantial, and is best done at centers with high patient numbers (143-145). In addition, the costs associated with procuring robotic equipment may limit the availability of this approach. Treatment outcomes are likely to improve as techniques are developed further, but current data indicate that open surgery may still be preferable.

\section{Cochrane Review}

A recently published Cochrane review evaluated benefits and harms of all the available interventions for VUR. Thirty-four randomized studies met the inclusion criteria (34). Antibiotic prophylaxis was reported to have little effect on the risk of UTI and to increase the likelihood of antibiotic resistance. The benefits with endoscopic injection or ureteral reimplantation vs. antibiotic treatment were deemed unclear due to insufficiencies in study design.

\section{MANAGEMENT RECOMMENDATIONS}

The main aim of VUR management recommendations is to ensure that each patient receives the most appropriate intervention for their individual needs. There are variations between countries in the approach to VUR management and in the specialty of the healthcare provider who first sees the patient. International variability is also encountered in the licensed 
indications for devices including the injectable agents used in endoscopic treatment.

\section{Developments Over the Last 20 Years}

The 1997 AUA guidelines recommended antibiotic prophylaxis as first-line treatment, with surgery (ureteral reimplantation) as second-line treatment for persistent cases or as first-line intervention in severe VUR (particularly in older children) (146). Endoscopic injection was not recommended for routine use at that time, and concerns we now have regarding antibiotic prophylaxis were less well-understood. In 2002, positive results obtained with endoscopic injection of NASHA/Dx led to the proposal of an updated treatment algorithm (147). For most patients, 1 year of antibiotic prophylaxis was recommended in the first instance. For those in whom VUR persisted to the end of the year, endoscopic injection was proposed. Ureteral reimplantation was considered appropriate for patients not responding to endoscopic treatment, and it was also recommended as first-line intervention in high-risk groups (children aged $>1$ year with grade $\mathrm{V}$ reflux, and those aged $>5$ years with grade bilateral III-IV reflux) (147).

Over the last 20 years, there has been a shift toward more conservative management of VUR. More emphasis is now placed on an individualized, risk-based approach, with less reliance on long-term antibiotic prophylaxis, reduced use of VCUG and a decline in surgical intervention (45). Also, patients with concurrent VUR and BBD are understood to have an increased risk of UTI vs. patients with VUR only, meaning that treatments for both conditions may be needed $(22,25)$. It remains unclear whether BBD should always be treated before VUR.

\section{Current Guidelines}

The European Association of Urology (EAU) guidelines on the management of VUR are 8 years old (69). They state prominently that "there is no consensus on the optimal management of VUR or on its diagnostic procedures, treatment options, or most effective timing of treatment." VUR guidelines from the American Urological Association (AUA) were updated more recently, in 2017, but these too include a comment that "the data were not sufficient to permit development of strict 'standards of care' in many instances" (68). This has undoubtedly contributed to the current variability in VUR management.

The EAU and AUA guidelines recommend VCUG in infants with prenatally diagnosed hydronephrosis, and siblings and offspring of VUR patients $(68,69)$. EAU guidelines also recommend VCUG examination in children with an fUTI or lower urinary tract dysfunction (69). For infants diagnosed in the first year of life, antibiotic prophylaxis is recommended as first-line treatment, with ureteral reimplantation or endoscopic treatment for those with breakthrough infections $(68,69)$. Antibiotic prophylaxis is also recommended in the EAU guidelines as initial treatment for children aged 1-5 years with grade III-V VUR, although ureteral reimplantation should be considered as an alternative in those with high-grade VUR (69). For children with lower urinary tract dysfunction (LUTS) as well as VUR, the EAU recommend that initial management should be focused on LUTS. Endoscopic treatment is recommended principally as an option for children with low grades of VUR (up to grade III) and, for high-risk patients with renal impairment, an "aggressive, multidisciplinary approach" is recommended (69). In the AUA guidelines, for patients aged $>1$ year and no BBD, antibiotic therapy is suggested as an option, while endoscopic injection or ureteral reimplantation are recommended for patients with recurrent UTIs or new renal abnormalities. For patients aged $>1$ year with concurrent VUR and BBD, the AUA guidelines recommend antibiotic therapy with $\mathrm{BBD}$ treatment (68). The AUA guidelines describe lower success rates with endoscopic injection vs. ureteral reimplantation, but definite recommendations on how to choose between these options are lacking (68).

Guidelines on managing patients with UTIs also include recommendations relating to VUR. The American Academy of Pediatrics (AAP) guidelines of 2011 were influential in reducing the use of VCUG. Before 2011, patients between 2 and 24 months of age with an fUTI routinely underwent VCUG assessment. In contrast, the 2011 guidelines recommended renal and bladder ultrasound assessment for patients with their first fUTI, and no VCUG among those without ultrasounddetectable abnormalities (148). This approach was reaffirmed by the AAP in 2016 (149). The UK National Institute for Health and Care Excellence (NICE) similarly recommend VCUG only in selected children with UTIs: those aged $<6$ months with atypical or recurrent UTIs (150). These UK guidelines recommend surgical treatment of VUR (either endoscopic injection or ureteral reimplantation) only for VUR patients with "symptomatic breakthrough

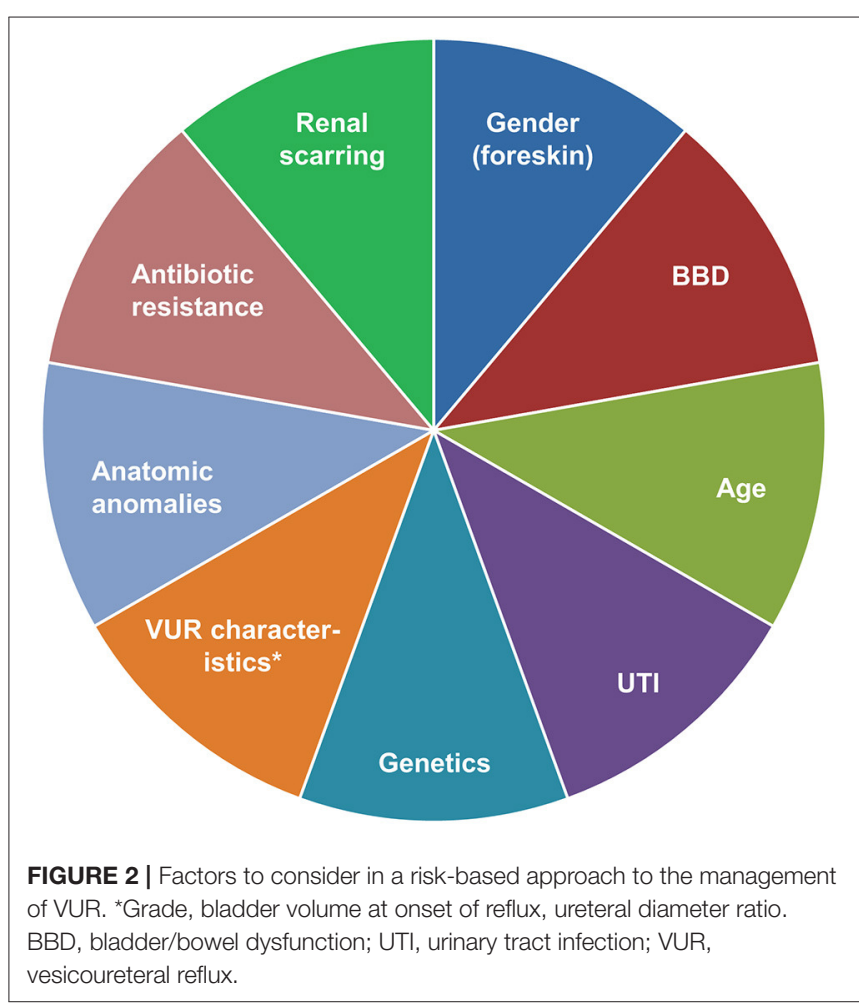


UTIs despite medical management and/or increased renal parenchymal defects."

\section{Current Opinion of the Authors}

In all patients with VUR, there is a need to balance risks, benefits and costs of treatment vs. risks (particularly to the kidneys) of not treating the condition (Figure 2) $(14,33,35,151)$. We believe that first-line endoscopic injection is preferable for many VUR patients requiring intervention. Ureteral reimplantation is usually performed in patients not responding to endoscopic injection, those with primary obstructive refluxing megaureter, and those with grade V VUR and concomitant narrowing of the vesicoureteral junction. For patients with VUR and bladder or bowel dysfunction (BBD), we recommend treating BBD as early as possible (before VUR intervention). However, in cases with recurrent breakthrough UTIs, endoscopic treatment or ureteral reimplantation should not be delayed and $\mathrm{BBD}$ therapy can still be undertaken as needed. We no longer support the routine use of long-term antibiotic prophylaxis for VUR. Long-term monitoring of patients with VCUG assessments after endoscopic treatment or ureteral reimplantation appears unnecessary, due to the high cure rates with both treatment options. Follow-up VCUGs are mainly triggered by the occurrence of symptomatic UTIs. Every decision needs to be taken with due consideration of the individual patient's history and current health status, risk of recurrent UTI, as well as the wishes of the patient and/or their parents.

\section{CONCLUSIONS}

Over the last 20 years, our understanding of VUR has increased considerably. A proportion of children with renal scarring after UTI (particularly those with grade III-V VUR and recurrent

\section{REFERENCES}

1. Mattoo TK. Vesicoureteral reflux and reflux nephropathy. Adv Chronic Kidney Dis. (2011) 18:348-54. doi: 10.1053/j.ackd.2011.07.006

2. Decter RM. Update on vesicoureteral reflux: pathogenesis, nephropathy, and management. Rev Urol. (2001) 3:172-8.

3. Blais AS, Bolduc S, Moore K. Vesicoureteral reflux: from prophylaxis to surgery. Can Urol Assoc J. (2017) 11:S13-8. doi: 10.5489/cuaj.4342

4. Sargent MA. What is the normal prevalence of vesicoureteral reflux? Pediatr Radiol. (2000) 30:587-93. doi: 10.1007/s002470000263

5. Capozza N, Gulia C, Heidari Bateni Z, Zangari A, Gigli S, Briganti $\mathrm{V}$, et al. Vesicoureteral reflux in infants: what do we know about the gender prevalence by age? Eur Rev Med Pharmacol Sci. (2017) 21:53219. doi: 10.26355/eurrev_201712_13916

6. Sjöström S, Jodal U, Sixt R, Bachelard M, Sillén U. Longitudinal development of renal damage and renal function in infants with high grade vesicoureteral reflux. J Urol. (2009) 181:2277-83. doi: 10.1016/j.juro.2009. 01.051

7. Swerkersson S, Jodal U, Sixt R, Stokland E, Hansson S. Relationship among vesicoureteral reflux, urinary tract infection and renal damage in children. J Urol. (2007) 178:647-51. doi: 10.1016/j.juro.2007. 04.004

8. Swerkersson S, Jodal U, Sixt R, Stokland E, Hansson S. Urinary tract infection in small children: the evolution of renal damage over time. Pediatr Nephrol. (2017) 32:1907-13. doi: 10.1007/s00467-017-3705-5
fUTI) are at risk of renal deterioration. Improved knowledge of how to identify such patients has led to an individualized, riskbased approach to the management of VUR and an overall shift to more conservative management of VUR. Surgical methods of ureteral reimplantation have progressed but our opinion is that endoscopic injection is frequently preferable, based on evidence from the last two decades confirming the long-term tolerability and durability of this procedure. Although a number of materials have been explored as injectable agents during the last 20 years, NASHA/Dx is widely considered the preferred choice with the strongest long-term efficacy and safety data. Key knowledge gaps include the need for better identification of children at risk of recurrent UTIs and future renal scarring, robust evidence from randomized controlled trials, further evaluation of the side effects of chronic antibiotic exposure, and an improved VUR grading system. These gaps will need to be addressed in the coming years to ensure that individual patients' needs are fulfilled to the greatest possible extent.

\section{AUTHOR CONTRIBUTIONS}

All authors reviewed the literature and collaborated in writing and editing the manuscript.

\section{FUNDING}

Medical writing support was funded by Palette Life Sciences. Palette Life Sciences reviewed the manuscript for scientific accuracy.

\section{ACKNOWLEDGMENTS}

The authors thank Ken Sutor of Ascendancy Medical Writing.

9. Hidas G, Billimek J, Nam A, Soltani T, Kelly MS, Selby B, et al. Predicting the risk of breakthrough urinary tract infections: primary vesicoureteral reflux. J Urol. (2015) 194:1396-401. doi: 10.1016/j.juro.2015. 06.019

10. Arlen AM, Alexander SE, Wald M, Cooper CS. Computer model predicting breakthrough febrile urinary tract infection in children with primary vesicoureteral reflux. J Pediatr Urol. (2016) 12:288 e1-5. doi: 10.1016/j.jpurol.2016.03.005

11. Keren R, Shaikh N, Pohl H, Gravens-Mueller L, Ivanova A, Zaoutis L, et al. Risk factors for recurrent urinary tract infection and renal scarring. Pediatrics. (2015) 136:e13-21. doi: 10.1542/peds.2015-0409

12. Singh-Grewal D, Macdessi J, Craig J. Circumcision for the prevention of urinary tract infection in boys: a systematic review of randomised trials and observational studies. Arch Dis Child. (2005) 90:853-8. doi: 10.1136/adc.2004.049353

13. Yilmaz I, Peru H, Yilmaz FH, Sekmenli T, Ciftci I, Kara F. Association of vesicoureteral reflux and renal scarring in urinary tract infections. Arch Argent Pediatr. (2018) 116:e542-e7. doi: 10.5546/aap.2018.eng.e542

14. Finkelstein J, Rague J, Varda B, Venna A, Shanahan M, Aihie N, et al. Renal scarring is associated with adverse renal outcomes during longitudinal assessment [MP64-14]. J Urol. (2019) 201(Suppl. 4):e9467. doi: 10.1097/01.JU.0000556906.25332.4c

15. Wennerström M, Hansson S, Jodal U, Stokland E. Disappearance of vesicoureteral reflux in children. Arch Pediatr Adolesc Med. (1998) 152:87983. doi: 10.1001/archpedi.152.9.879 
16. Schwab CW, Jr., Wu HY, Selman H, Smith GH, Snyder HM, III, Canning DA. Spontaneous resolution of vesicoureteral reflux: a 15-year perspective. J Urol. (2002) 168:2594-9. doi: 10.1097/01.ju.0000037530. $11361.8 \mathrm{~b}$

17. Sjöström S, Sillén U, Jodal U, Sameby L, Sixt R, Stokland E. Predictive factors for resolution of congenital high grade vesicoureteral reflux in infants: results of univariate and multivariate analyses. J Urol. (2010) 183:117784. doi: 10.1016/j.juro.2009.11.055

18. Knudson MJ, Austin JC, McMillan ZM, Hawtrey CE, Cooper CS. Predictive factors of early spontaneous resolution in children with primary vesicoureteral reflux. J Urol. (2007) 178:1684-8. doi: 10.1016/j.juro.2007.03.161

19. Nepple KG, Knudson MJ, Austin JC, Cooper CS. Abnormal renal scans and decreased early resolution of low grade vesicoureteral reflux. J Urol. (2008) 180:1643-7. doi: 10.1016/j.juro.2008.03.102

20. Nepple KG, Knudson MJ, Austin JC, Wald M, Makhlouf AA, Niederberger $\mathrm{CS}$, et al. Adding renal scan data improves the accuracy of a computational model to predict vesicoureteral reflux resolution. J Urol. (2008) 180:164852. doi: 10.1016/j.juro.2008.03.109

21. Nepple KG, Arlen AM, Austin JC, Cooper CS. The prognostic impact of an abnormal initial renal ultrasound on early reflux resolution. J Pediatr Urol. (2011) 7:462-6. doi: 10.1016/j.jpurol.2010.07.003

22. Garcia-Roig ML, Kirsch AJ. Urinary tract infection in the setting of vesicoureteral reflux. F1000Res. (2016) 5:F1000. doi: 10.12688/f1000research.8390.1

23. Kirsch AJ, Arlen AM, Leong T, Merriman LS, Herrel LA, Scherz HC, et al. Vesicoureteral reflux index (VURx): a novel tool to predict primary reflux improvement and resolution in children less than 2 years of age. J Pediatr Urol. (2014) 10:1249-54. doi: 10.1016/j.jpurol.2014.06.019

24. Alexander SE, Arlen AM, Storm DW, Kieran K, Cooper CS. Bladder volume at onset of vesicoureteral reflux is an independent risk factor for breakthrough febrile urinary tract infection. J Urol. (2015) 193:13426. doi: 10.1016/j.juro.2014.10.002

25. Meena J, Mathew G, Hari P, Sinha A, Bagga A. Prevalence of bladder and bowel dysfunction in toilet-trained children with urinary tract infection and/or primary vesicoureteral reflux: a systematic review and meta-analysis. Front Pediatr. (2020) 8:84. doi: 10.3389/fped.2020.00084

26. Sillén U. Bladder dysfunction and vesicoureteral reflux. Adv Urol. (2008) 815472. doi: 10.1155/2008/815472

27. Elder JS, Diaz M. Vesicoureteral reflux-the role of bladder and bowel dysfunction. Nat Rev Urol. (2013) 10:640-8. doi: 10.1038/nrurol.2013.221

28. Stenbäck A, Olafsdottir T, Sköldenberg E, Barker G, Stenberg A, Läckgren G. Proprietary non-animal stabilized hyaluronic acid/dextranomer gel (NASHA/Dx) for endoscopic treatment of grade IV vesicoureteral reflux: long-term observational study. J Pediatr Urol. (2020) 16:328 e19. doi: 10.1016/j.jpurol.2020.04.008

29. Kraft KH, Molitierno JA, Jr., Dewhurst L, Geers C, Gunderson K, Scherz HC, et al. Is endoscopic injection therapy a reasonable treatment option for lowgrade vesicoureteral reflux in association with overactive bladder? Urology. (2011) 78:675-8. doi: 10.1016/j.urology.2010.12.084

30. Läckgren G, Sköldenberg E, Stenberg A. Endoscopic treatment with stabilized nonanimal hyaluronic acid/dextranomer gel is effective in vesicoureteral reflux associated with bladder dysfunction. J Urol. (2007) 177:1124-8. doi: 10.1016/j.juro.2006.10.094

31. Hollowell JG. Outcome of pregnancy in women with a history of vesico-ureteric reflux. BJU Int. (2008) 102:7804. doi: 10.1111/j.1464-410X.2008.07671.x

32. Roihuvuo-Leskinen HM, Vainio MI, Niskanen KM, Lahdes-Vasama TT, Pregnancies in women with childhood vesicoureteral reflux. Acta Obstet Gynecol Scand. (2015) 94:847-51. doi: 10.1111/aogs.12664

33. Edwards A, Peters CA. Managing vesicoureteral reflux in children: making sense of all the data. F1000Res. (2019) 8:F1000. doi: 10.12688/f1000research.16534.1

34. Williams G, Hodson EM, Craig JC. Interventions for primary vesicoureteric reflux. Cochrane Database Syst Rev. (2019) 2:CD001532. doi: 10.1002/14651858.CD001532.pub5

35. Kirsch AJ, Arlen AM. Evolving surgical management of pediatric vesicoureteral reflux: is open ureteral reimplantation still the 'Gold Standard'? Int Braz J Urol. (2020) 46:31421. doi: 10.1590/S1677-5538.IBJU.2020.99.05

36. Lee LC, Lorenzo AJ, Koyle MA. The role of voiding cystourethrography in the investigation of children with urinary tract infections. Can Urol Assoc J. (2016) 10:210-4. doi: 10.5489/cuaj.3610

37. Frimberger D, Bauer SB, Cain MP, Greenfield SP, Kirsch AJ, Ramji F, et al. Establishing a standard protocol for the voiding cystourethrography. J Pediatr Urol. (2016) 12:362-6. doi: 10.1016/j.jpurol.2016.11.001

38. Arlen AM, Cooper CS. New trends in voiding cystourethrography and vesicoureteral reflux: who, when and how? Int J Urol. (2019) 26:4405. doi: 10.1111/iju.13915

39. Celebi S, Ozaydin S, Bastas CB, Kuzdan O, Erdogan C, Yazici M, et al. Reliability of the grading system for voiding cystourethrograms in the management of vesicoureteral reflux: an interrater comparison. Adv Urol. (2016) 2016:1684190. doi: 10.1155/2016/1684190

40. Metcalfe CB, Macneily AE, Afshar K. Reliability assessment of international grading system for vesicoureteral reflux. J Urol. (2012) 188:14902. doi: 10.1016/j.juro.2012.02.015

41. Ozaydin S, Celebi S, Caymaz I, Besik C, Karaaslan B, Kuzdan O, et al. Increasing the reliability of the grading system for voiding cystourethrograms using ultrasonography: an inter-rater comparison. Nephrourol Mon. (2016) 8:e38685. doi: 10.5812/numonthly.38685

42. Schaeffer AJ, Greenfield SP, Ivanova A, Cui G, Zerin JM, Chow JS, et al. Reliability of grading of vesicoureteral reflux and other findings on voiding cystourethrography. J Pediatr Urol. (2017) 13:1928. doi: 10.1016/j.jpurol.2016.06.020

43. Janssen KM, Kirsch AJ, Crisotomo-Wynne TC, Leong T, Cuda SP, Arlen AM. Standardized protocol for voiding cystourethrogram: are recommendations being followed? J Pediatr Urol. (2021) 17:66.e1e6. doi: 10.1016/j.jpurol.2020.10.009

44. Polito C, Moggio G, La Manna A, Cioce F, Cappabianca S, Di Toro R. Cyclic voiding cystourethrography in the diagnosis of occult vesicoureteric reflux. Pediatr Nephrol. (2000) 14:39-41. doi: 10.1007/s004670050010

45. Garcia-Roig M, Travers C, McCracken CE, Kirsch AJ. National trends in the management of primary vesicoureteral reflux in children. J Urol. (2018) 199:287-93. doi: 10.1016/j.juro.2017.09.073

46. Anwar T, Cooper CS, Lockwood G, Ferguson KJ, Barlow PB, Storm DW. Assessment and validation of a screening questionnaire for the diagnosis of pediatric bladder and bowel dysfunction. J Pediatr Urol. (2019) 15:528 e1-8. doi: 10.1016/j.jpurol.2019.07.016

47. Arlen AM, Scherz HC, Filimon E, Leong T, Kirsch AJ. Is routine voiding cystourethrogram necessary following double hit for primary vesicoureteral reflux? J Pediatr Urol. (2015) 11:40.e1-5. doi: 10.1016/j.jpurol.2014.11.011

48. Haid B, Berger C, Roesch J, Becker T, Koen M, Langsteger W, et al. Persistence and recurrence of vesicoureteric reflux in children after endoscopic therapy-implications of a risk-adapted follow-up. Cent European J Urol. (2015) 68:389-95. doi: 10.5173/ceju.2015.560

49. Hung TW, Tsai JD, Liao PF, Sheu JN. Role of renal ultrasonography in predicting vesicoureteral reflux and renal scarring in children hospitalized with a first febrile urinary tract infection. Pediatr Neonatol. (2016) 57:1139. doi: 10.1016/j.pedneo.2015.06.001

50. Zhang X, Xu H, Zhou L, Cao Q, Shen Q, Sun L, et al. Accuracy of early DMSA scan for VUR in young children with febrile UTI. Pediatrics. (2014) 133:e30-8. doi: 10.1542/peds.2012-2650

51. Sheu JN, Wu KH, Chen SM, Tsai JD, Chao YH, Lue KH. Acute 99mTc DMSA scan predicts dilating vesicoureteral reflux in young children with a first febrile urinary tract infection: a population-based cohort study. Clin Nucl Med. (2013) 38:163-8. doi: 10.1097/RLU.0b013e318279f112

52. Berry CS, Vander Brink BA, Koff SA, Alpert SA, Jayanthi VR. Is VCUG still indicated following the first episode of urinary tract infection in boys? Urology. (2012) 80:1351-5. doi: 10.1016/j.urology.2012.03.073

53. Robinson JL, Finlay JC, Lang ME, Bortolussi R, Canadian Paediatric Society ID, Immunization Committee CPC. Urinary tract infections in infants and children: diagnosis and management. Paediatr Child Health. (2014) 19:31525. doi: $10.1093 / \mathrm{pch} / 19.6 .315$

54. Johnston DL, Qureshi AH, Irvine RW, Giel DW, Hains DS. Contemporary management of vesicoureteral reflux. Curr Treat Options Pediatr. (2016) 2:82-93. doi: 10.1007/s40746-016-0045-9 
55. Arlen AM, Kirsch AJ, Leong T, Cooper CS. Validation of the ureteral diameter ratio for predicting early spontaneous resolution of primary vesicoureteral reflux. J Pediatr Urol. (2017) 13:383 e1-6. doi: 10.1016/j.jpurol.2017.01.012

56. Cooper CS, Alexander SE, Kieran K, Storm DW. Utility of the distal ureteral diameter on VCUG for grading VUR. J Pediatr Urol. (2015) 11:183.e16. doi: 10.1016/j.jpurol.2015.04.009

57. Cooper CS, Birusingh KK, Austin JC, Knudson MJ, Brophy PD. Distal ureteral diameter measurement objectively predicts vesicoureteral reflux outcome. J Pediatr Urol. (2013) 9:99-103. doi: 10.1016/j.jpurol.2011.12.011

58. Arlen AM, Leong T, Guidos PJ, Alexander SE, Cooper CS. Distal ureteral diameter ratio is predictive of breakthrough febrile urinary tract infection. $J$ Urol. (2017) 198:1418-23. doi: 10.1016/j.juro.2017.06.095

59. Swanton AR, Arlen AM, Alexander SE, Kieran K, Storm DW, Cooper CS. Inter-rater reliability of distal ureteral diameter ratio compared to grade of VUR. J Pediatr Urol. (2017) 13:207.e1-e5. doi: 10.1016/j.jpurol.2016.10.021

60. Knudson MJ, Austin JC, Wald M, Makhlouf AA, Niederberger CS, Cooper CS. Computational model for predicting the chance of early resolution in children with vesicoureteral reflux. J Urol. (2007) 178:18247. doi: 10.1016/j.juro.2007.05.093

61. Arlen AM, Garcia-Roig M, Weiss AD, Leong T, Cooper CS, Kirsch AJ. Vesicoureteral reflux index: 2-institution analysis and validation. J Urol. (2016) 195:1294-9. doi: 10.1016/j.juro.2015.03.094

62. Garcia-Roig M, Ridley DE, McCracken C, Arlen AM, Cooper CS, Kirsch AJ. Vesicoureteral reflux index: predicting primary vesicoureteral reflux resolution in children diagnosed after age 24 months. J Urol. (2017) 197:1150-7. doi: 10.1016/j.juro.2016.12.008

63. Arlen AM, Leong T, Wu CQ, Traore EJ, Cooper CS, Kirsch AJ. Predicting breakthrough urinary tract infection: comparative analysis of vesicoureteral reflux index, reflux grade and ureteral diameter ratio. J Urol. (2020) 204:5727. doi: 10.1097/JU.0000000000001035

64. Chua ME, Mendoza JS, Ming JM, Dy JS, Gomez O. Diagnostic accuracy of contrast-enhanced voiding urosonogram using second-generation contrast with harmonic imaging (CEVUS-HI) study for assessment of vesicoureteral reflux in children: a meta-analysis. World J Urol. (2019) 37:224555. doi: 10.1007/s00345-018-2587-x

65. Ntoulia A, Back SJ, Shellikeri S, Poznick L, Morgan T, Kerwood J, et al. Contrast-enhanced voiding urosonography (ceVUS) with the intravesical administration of the ultrasound contrast agent Optison for vesicoureteral reflux detection in children: a prospective clinical trial. Pediatr Radiol. (2018) 48:216-26. doi: 10.1007/s00247-017-4026-3

66. Zhang W, Cai B, Zhang X, Zhou J, Qiu L, Yi H. Contrast-enhanced voiding urosonography with intravesical administration of ultrasound contrast agent for the diagnosis of pediatric vesicoureteral reflux. Exp Ther Med. (2018) 16:4546-52. doi: 10.3892/etm.2018.6793

67. Park YS. Renal scar formation after urinary tract infection in children. Korean J Pediatr. (2012) 55:367-70. doi: 10.3345/kjp.2012.55.10.367

68. Peters CA, Skoog SJ, Arant BS, Jr., Copp HL, Elder JS, Hudson RG, et al. Management and Screening of Primary Vesicoureteral Reflux in Children [AUA guideline]. Available online at: https://www.auanet.org/guidelines/ vesicoureteral-reflux-guideline (accessed March, 2021).

69. Tekgül S, Riedmiller H, Hoebeke P, Kocvara R, Nijman RJ, Radmayr C, et al. EAU guidelines on vesicoureteral reflux in children. Eur Urol. (2012) 62:534-42. doi: 10.1016/j.eururo.2012.05.059

70. Brandström P, Jodal U, Sillen U, Hansson S. The Swedish reflux trial: review of a randomized, controlled trial in children with dilating vesicoureteral reflux. J Pediatr Urol. (2011) 7:594-600. doi: 10.1016/j.jpurol.2011. 05.006

71. Rivur Trial Investigators, Hoberman A, Greenfield SP, Mattoo TK, Keren R, Mathews R, et al. Antimicrobial prophylaxis for children with vesicoureteral reflux. N Engl J Med. (2014) 370:2367-76. doi: 10.1056/NEJMoa1401811

72. Brandström P, Esbjörner E, Herthelius M, Swerkersson S, Jodal U, Hansson S. The Swedish reflux trial in children: III. Urinary tract infection pattern. $J$ Urol. (2010) 184:286-91. doi: 10.1016/j.juro.2010.01.061

73. Shaikh N, Mattoo TK, Keren R, Ivanova A, Cui G, MoxeyMims M, et al. Early antibiotic treatment for pediatric febrile urinary tract infection and renal scarring. JAMA Pediatr. (2016) 170:848-54. doi: 10.1001/jamapediatrics.2016.1181
74. Coulthard MG, Lambert HJ, Vernon SJ, Hunter EW, Keir MJ, Matthews JN. Does prompt treatment of urinary tract infection in preschool children prevent renal scarring: mixed retrospective and prospective audits. Arch Dis Child. (2014) 99:342-7. doi: 10.1136/archdischild-2013-304428

75. McGrath M, Ramesh S, Webster A, Palczewsk K, Braga LH. Challenging the status quo: a prospective study of early discontinuation of continuous antibiotic prophylaxis in children with vesicoureteral reflux [MP64-04]. J Urol. (2019) 201(Suppl. 4):e942. doi: 10.1097/01.JU.0000556896.02462.e6

76. Hensle TW, Hyun G, Grogg AL, Eaddy M. Part 2: examining pediatric vesicoureteral reflux: a real-world evaluation of treatment patterns and outcomes. Curr Med Res Opin. (2007) 23(Suppl. 4):S7-13. doi: 10.1185/030079907X226221

77. Lee T, Park JM. Vesicoureteral reflux and continuous prophylactic antibiotics. Investig Clin Urol. (2017) 58:S327. doi: 10.4111/icu.2017.58.S1.S32

78. Cooper CS. What good or harm comes from prophylactic antibiotics in children with vesicoureteral reflux? Nat Clin Pract Urol. (2006) 3:4167. doi: $10.1038 /$ ncpuro0523

79. Guidos PJ, Arlen AM, Leong T, Bonnett MA, Cooper CS. Impact of continuous low-dose antibiotic prophylaxis on growth in children with vesicoureteral reflux. J Pediatr Urol. (2018) 14:325.e1-7. doi: 10.1016/j.jpurol.2018.07.007

80. Kho ZY, Lal SK. The human gut microbiome-a potential controller of wellness and disease. Front Microbiol. (2018) 9:1835. doi: 10.3389/fmicb.2018.01835

81. Cooper CS. Fat, demented and stupid: an unrecognized legacy of pediatric urology? J Pediatr Urol. (2017) 13:341-4. doi: 10.1016/j.jpurol.2017.04.027

82. Palmer LS, Seideman CA, Lotan Y. Cost-effectiveness of antimicrobial prophylaxis for children in the RIVUR trial. World J Urol. (2018) 36:14417. doi: 10.1007/s00345-018-2302-y

83. Shaikh N, Rajakumar V, Peterson CG, Gorski J, Ivanova A, Gravens Muller L, et al. Cost-utility of antimicrobial prophylaxis for treatment of children with vesicoureteral reflux. Front Pediatr. (2019) 7:530. doi: 10.3389/fped.2019.00530

84. Wang H, Li M, Bertsimas D, Estrada C, Nelson C. Selecting children with VUR who are most likely to benefit from antibiotic prophylaxis: application of machine learning to RIVUR data [MP64-03]. J Urol. (2019) 201(Suppl. 4):e941. doi: 10.1097/01.JU.0000556895.20387.16

85. Friedmacher F, Colhoun E, Puri P. Endoscopic injection of dextranomer/hyaluronic acid as first line treatment in 851 consecutive children with high grade vesicoureteral reflux: efficacy and long-term results. J Urol. (2018) 200:650-5. doi: 10.1016/j.juro.2018.03.074

86. Hunziker M, Mohanan N, Puri P. Dextranomer/hyaluronic acid endoscopic injection is effective in the treatment of intermediate and high grade vesicoureteral reflux in patients with complete duplex systems. J Urol. (2013) 189:1876-81. doi: 10.1016/j.juro.2012.11.048

87. Puri P, Kutasy B, Colhoun E, Hunziker M. Single center experience with endoscopic subureteral dextranomer/hyaluronic acid injection as first line treatment in 1,551 children with intermediate and high grade vesicoureteral reflux. J Urol. (2012) 188:1485-9. doi: 10.1016/j.juro.2012.02.023

88. Ramsay S, Blais AS, Morin F, Moore K, Cloutier J, Bolduc S. Polyacrylamide hydrogel as a bulking agent for the endoscopic treatment of vesicoureteral reflux: long-term results and safety. J Urol. (2017) 197:963-7. doi: 10.1016/j.juro.2016.08.093

89. Puri P, Pirker M, Mohanan N, Dawrant M, Dass L, Colhoun E. Subureteral dextranomer/hyaluronic acid injection as first line treatment in the management of high grade vesicoureteral reflux. J Urol. (2006) 176:18569. doi: 10.1016/j.juro.2006.03.124

90. De Badiola FI, Soria R, Vagni RL, Ormaechea MN, Moldes JM, Benmaor C. Results of treatment of grades IV and $\mathrm{V}$ vesicoureteral reflux with endoscopic injection of polyacrylate polyalcohol copolymer. Front Pediatr. (2013) 1:32. doi: 10.3389/fped.2013.00032

91. Bayne AP, Roth DR. Dextranomer/hyaluronic injection for the management of vesicoureteric reflux in complete ureteral duplication: should age and gender be factors in decision making? J Endourol. (2010) 24:10136. doi: 10.1089/end.2009.0412

92. Calisti A, Perrotta ML, Coletta R, Olivieri C, Briganti V, Oriolo L, et al. An allendo approach to complete ureteral duplications complicated by ureterocele 
and/or vesicoureteral reflux: feasibility, limitations, and results. Int J Pediatr. (2011) 2011:103067. doi: 10.1155/2011/103067

93. Murphy AM, Ritch CR, Reiley EA, Hensle TW. Endoscopic management of vesicoureteral reflux in adult women. BJU Int. (2011) 108:2524. doi: 10.1111/j.1464-410X.2010.09824.x

94. Turk A, Selimoglu A, Demir K, Celik O, Saglam E, Tarhan F. Endoscopic treatment of vesicoureteral reflux with polyacrylate polyalcohol copolymer and dextranomer/hyaluronic acid in adults. Int Braz J Urol. (2014) 40:37983. doi: 10.1590/s1677-5538.ibju.2014.03.12

95. Akiki A, Boissier R, Delaporte V, Maurin C, Gaillet S, Karsenty G, et al. Endoscopic treatment of symptomatic vesicoureteral reflux after renal transplantation. J Urol. (2015) 193:225-9. doi: 10.1016/j.juro.2014.07.103

96. Moore K, Bolduc S. Treatment of vesicoureteral reflux in adults by endoscopic injection. Urology. (2011) 77:12847. doi: 10.1016/j.urology.2010.12.080

97. Natsheh A, Shenfeld OZ, Farkas A, Chertin B. Endoscopic treatment of vesicoureteral reflux in an adult population: can we teach our adult urology colleagues? J Pediatr Urol. (2010) 6:600-4. doi: 10.1016/j.jpurol.2010.01.012

98. Romero NP, Romo MI, Vegas AG, Izquierdo JB, Varela JC, Arteche AH, et al. Deflux injections for vesicoureteral reflux in transplanted kidneys. Transplant Proc. (2010) 42:2892-5. doi: 10.1016/j.transproceed.2010.07.074

99. Sheth KR, White JT, Stanasel I, Janzen N, Mittal A, Koh CJ, et al. Comparing treatment modalities for transplant kidney vesicoureteral reflux in the pediatric population. J Pediatr Urol. (2018) 14:554.e1e6. doi: 10.1016/j.jpurol.2018.07.006

100. Wang HH, Ding WF, Chu SH, Chiang YJ, Liu KL, Lin KJ, et al. Endoscopic Treatment for post-transplant vesicoureteral reflux. Transplant Proc. (2019) 51:1420-3. doi: 10.1016/j.transproceed.2019.03.018

101. Williams MA, Giel DW, Colleen Hastings M. Endoscopic Deflux injection for pediatric transplant reflux: a feasible alternative to open ureteral reimplant. J Pediatr Urol. (2008) 4:341-4. doi: 10.1016/j.jpurol.2008.04.003

102. Wu HY, Concepcion W, Grimm PC. When does vesicoureteral reflux in pediatric kidney transplant patients need treatment? Pediatr Transplant. (2018) 22:e13299. doi: 10.1111/petr.13299

103. Balaban M, Ozkaptan O, Cubuk A, Sahan A, Duzenli M, Tuncer M. Endoscopic treatment of symptomatic VUR disease after the renal transplantation: analysis of 49 cases. Clin Exp Nephrol. (2020) (Epub ahead of print). doi: 10.1007/s10157-020-01847-2

104. Läckgren G, Wåhlin N, Sköldenberg E, Neveus T, Stenberg A. Endoscopic treatment of vesicoureteral reflux with dextranomer/hyaluronic acid copolymer is effective in either double ureters or a small kidney. J Urol. (2003) 170:1551-5. doi: 10.1097/01.ju.0000084672.98131.f7

105. Läckgren G, Wåhlin N, Sköldenberg E, Stenberg A. Long-term follow-up of children treated with dextranomer/hyaluronic acid copolymer for vesicoureteral reflux. J Urol. (2001) 166:188792. doi: 10.1016/s0022-5347(05)65713-8

106. Dogan HS, Altan M, Citamak B, Bozaci AC, Koni A, Tekgul S. Factors affecting the success of endoscopic treatment of vesicoureteral reflux and comparison of two dextranomer based bulking agents: does bulking substance matter? J Pediatr Urol. (2015) 11:90.e1-5. doi: 10.1016/j.jpurol.2014.12.009

107. Leung L, Chan IHY, Chung PHY, Lan LCL, Tam PKH, Wong KKY. Endoscopic injection for primary vesicoureteric reflux: predictors of resolution and long term efficacy. J Pediatr Surg. (2017) 52:20669. doi: 10.1016/j.jpedsurg.2017.08.033

108. Kirsch AJ, Perez-Brayfield MR, Scherz HC. Minimally invasive treatment of vesicoureteral reflux with endoscopic injection of dextranomer/hyaluronic acid copolymer: the Children's Hospitals of Atlanta experience. J Urol. (2003) 170:211-5. doi: 10.1097/01.ju.0000072523.43060.a0

109. Payza AD, Hosgor M, Serdaroglu E, Sencan A. Can distal ureteral diameter measurement predict primary vesicoureteral reflux clinical outcome and success of endoscopic injection? J Pediatr Urol. (2019) 15:515.e1e8. doi: 10.1016/j.jpurol.2019.07.005

110. Baydilli N, Selvi I, Pinarbasi AS, Akinsal EC, Demirturk HC, Tosun H, et al. Additional VCUG-related parameters for predicting the success of endoscopic injection in children with primary vesicoureteral reflux. J Pediatr Urol. (2020) (epub ahead of print). doi: 10.1016/j.jpurol.2020.11.018
111. Escala Aguirre JM, Cadena Gonzalez Y, Retamal Pinto G, Lopez Egana PJ, Letelier Cancino N, Zubieta Acuna R. Endoscopic treatment of vesicoureteral reflux (VUR). Comparison of various substances. Long-term results. Arch Esp Urol. (2008) 61:297-300. doi: 10.4321/s0004-06142008000200028

112. Haferkamp A, Contractor H, Mohring K, Staehler G, Dorsam J. Failure of subureteral bovine collagen injection for the endoscopic treatment of primary vesicoureteral reflux in long-term follow-up. Urology. (2000) 55:759-63. doi: 10.1016/s0090-4295(00)00494-5

113. Läckgren G, Wåhlin N, Stenberg A. Endoscopic treatment of children with vesico-ureteric reflux. Acta Paediatr Suppl. (1999) 88:62-71.

114. Bhatti HA, Khattak H, Boston VE. Efficacy and causes of failure of endoscopic subureteric injection of Teflon in the treatment of primary vesicoureteric reflux. Br J Urol. (1993) 71:221-5.

115. Henly DR, Barrett DM, Weiland TL, O'Connor MK, Malizia AA, Wein AJ. Particulate silicone for use in periurethral injections: local tissue effects and search for migration. J Urol. (1995) 153:2039-43.

116. Starmer B, McAndrew F, Corbett H. A review of novel STING bulking agents. J Pediatr Urol. (2019) 15:484-90. doi: 10.1016/j.jpurol.2019.08.018

117. Pazeto CL, Nascimento FJ, Santiago LHS, Glina S. Idiosyncratic reaction after injection of polyacrylate-polyalcohol copolymer. Int Braz J Urol. (2018) 44:831-4. doi: 10.1590/S1677-5538.IBJU.2017.0446

118. Kajbafzadeh AM, Sabetkish S, Khorramirouz R, Sabetkish N. Comparison of histopathological characteristics of polyacrylate polyalcohol copolymer with dextranomer/hyaluronic acid after injection beneath the bladder mucosa layer: a rabbit model. Int Urol Nephrol. (2017) 49:747-52. doi: 10.1007/s11255-017-1540-z

119. Park K, Nishiwaki F, Kabashima K, Miyachi Y. A case of foreign-body granuloma of the glabella due to polyacrylamide filler and an intractable ulcer after skin biopsy: an immunohistochemical evaluation of inflammatory changes. Case Rep Dermatol. (2013) 5:181-5. doi: 10.1159/000353346

120. Amin SP, Marmur ES, Goldberg DJ. Complications from injectable polyacrylamide gel, a new nonbiodegradable soft tissue filler. Dermatol Surg. (2004) 30:1507-9. doi: 10.1111/j.1524-4725.2004.30551.x

121. Garcia-Aparicio L, Blazquez-Gomez E, Martin O, Perez-Bertolez S, Arboleda J, Soria A, et al. Randomized clinical trial between polyacrylate-polyalcohol copolymer (PPC) and dextranomer-hyaluronic acid copolymer (Dx/HA) as bulking agents for endoscopic treatment of primary vesicoureteral reflux (VUR). World J Urol. (2018) 36:1651-6. doi: 10.1007/s00345-018-2314-7

122. Alizadeh F, Omidi I, Haghdani S, Hatef Khorrami M, Izadpanahi MH, Mohammadi Sichani M. A comparison between dextranomer/ hyaluronic acid and polyacrylate polyalcohol copolymer as bulking agents for treating primary vesicoureteral reflux. Urol J. (2018) 16:1749. doi: $10.22037 /$ uj.v0i0.4156

123. Blais AS, Morin F, Cloutier J, Moore K, Bolduc S. Efficacy of dextranomer hyaluronic acid and polyacrylamide hydrogel in endoscopic treatment of vesicoureteral reflux: a comparative study. Can Urol Assoc J. (2015) 9:2026. doi: $10.5489 /$ cuaj.2964

124. Warchol S, Krzemien G, Szmigielska A, Bombinski P, Brzewski M, Dudek-Warchol T. Comparison of results of endoscopic correction of vesicoureteral reflux in children using two bulking substances: dextranomer/hyaluronic acid copolymer (Deflux) versus polyacrylatepolyalcohol copolymer (Vantris). J Pediatr Urol. (2016) 12:256.e12564. doi: 10.1016/j.jpurol.2016.04.006

125. Kobelt G, Canning DA, Hensle TW, Läckgren G. The costeffectiveness of endoscopic injection of dextranomer/hyaluronic acid copolymer for vesicoureteral reflux. J Urol. (2003) 169:14804. doi: 10.1097/01.ju.0000056638.75652.54

126. Benoit RM, Peele PB, Docimo SG. The cost-effectiveness of dextranomer/hyaluronic acid copolymer for the management of vesicoureteral reflux. 1: substitution for surgical management. J Urol. (2006) 176:1588-92. doi: 10.1016/j.juro.2006.06.031

127. Saperston K, Smith J, Putman S, Matern R, Foot L, Wallis C, et al. Endoscopic subureteral injection is not less expensive than outpatient open reimplantation for unilateral vesicoureteral reflux. J Urol. (2008) 180:16269. doi: 10.1016/j.juro.2008.05.124

128. Esposito C, Escolino M, Lopez M, Farina A, Cerulo M, Savanelli A, et al. Surgical management of pediatric vesicoureteral reflux: a comparative study 
between endoscopic, laparoscopic, and open surgery. J Laparoendosc $A d v$ Surg Tech A. (2016) 26:574-80. doi: 10.1089/lap.2016.0055

129. Ure I, Gurocak S, Tan O, Farahvash A, Senol C, Gumustas H, et al. Subureteral injection with small-size dextranomer/hyaluronic acid copolymer: is it really efficient? Biomed Res Int. (2016) 2016:2168753. doi: 10.1155/2016/2168753

130. Hubert KC, Kokorowski PJ, Huang L, Prasad MM, Rosoklija I, Retik AB, et al. Durability of antireflux effect of ureteral reimplantation for primary vesicoureteral reflux: findings on long-term cystography. Urology. (2012) 79:675-9. doi: 10.1016/j.urology.2011.11.005

131. Silay MS, Turan T, Kayali Y, Basibuyuk I, Gunaydin B, Caskurlu $\mathrm{T}$, et al. Comparison of intravesical (Cohen) and extravesical (Lich-Gregoir) ureteroneocystostomy in the treatment of unilateral primary vesicoureteric reflux in children. J Pediatr Urol. (2018) 14:65.e1-e4. doi: 10.1016/j.jpurol.2017.09.014

132. Harel M, Herbst KW, Silvis R, Makari JH, Ferrer FA, Kim C. Objective pain assessment after ureteral reimplantation: comparison of open versus robotic approach. J Pediatr Urol. (2015) 11:82.e1e8. doi: 10.1016/j.jpurol.2014.12.007

133. Sung J, Skoog S. Surgical management of vesicoureteral reflux in children. Pediatr Nephrol. (2012) 27:551-61. doi: 10.1007/s00467-011-1933-7

134. Wang HH, Tejwani R, Cannon GM, Jr., Gargollo PC, Wiener JS, Routh JC. Open versus minimally invasive ureteroneocystostomy: a population-level analysis. J Pediatr Urol. (2016) 12:232.e1e6. doi: 10.1016/j.jpurol.2016.03.014

135. Kurtz MP, Leow JJ, Varda BK, Logvinenko T, Yu RN, Nelson CP, et al. Robotic versus open pediatric ureteral reimplantation: costs and complications from a nationwide sample. J Pediatr Urol. (2016) 12:408.e1e6. doi: 10.1016/j.jpurol.2016.06.016

136. Yeung CK, Chowdhary SK, Sreedhar B. Minimally invasive management for vesicoureteral reflux in infants and young children. Clin Perinatol. (2017) 44:835-49. doi: 10.1016/j.clp.2017.08.008

137. Riquelme M, Lopez M, Landa S, Mejia F, Aranda A, Rodarte-Shade $\mathrm{M}$, et al. Laparoscopic extravesical ureteral reimplantation (LEVUR): a multicenter experience with 95 cases. Eur J Pediatr Surg. (2013) 23:1437. doi: $10.1055 / \mathrm{s}-0032-1329708$

138. Farina A, Esposito C, Escolino M, Lopez M, Settimi A, Varlet F. Laparoscopic extravesical ureteral reimplantation (LEVUR): a systematic review. Transl Pediatr. (2016) 5:291-4. doi: 10.21037/tp.2016.10.01

139. Boysen WR, Akhavan A, Ko J, Ellison JS, Lendvay TS, Huang J, et al. Prospective multicenter study on robot-assisted laparoscopic extravesical ureteral reimplantation (RALUR-EV): outcomes and complications. J Pediatr Urol. (2018) 14:262.e1-e6. doi: 10.1016/j.jpurol.2018.01.020

140. Herz D, Fuchs M, Todd A, McLeod D, Smith J. Robot-assisted laparoscopic extravesical ureteral reimplant: a critical look at surgical outcomes. J Pediatr Urol. (2016) 12:402.e1-e9. doi: 10.1016/j.jpurol.2016.05.042

141. Arlen AM, Broderick KM, Travers C, Smith EA, Elmore JM, Kirsch AJ. Outcomes of complex robot-assisted extravesical ureteral reimplantation in the pediatric population. J Pediatr Urol. (2016) 12:169.e1-e6. doi: 10.1016/j.jpurol.2015.11.007

142. Kawal T, Srinivasan AK, Chang J, Long C, Chu D, Shukla AR. Robotic-assisted laparoscopic ureteral re-implant (RALUR): Can post- operative urinary retention be predicted? J Pediatr Urol. (2018) 14:323.e1e5. doi: 10.1016/j.jpurol.2018.05.010

143. Bach C, Miernik A, Schonthaler M. Training in robotics: the learning curve and contemporary concepts in training. Arab J Urol. (2014) 12:5861. doi: 10.1016/j.aju.2013.10.005

144. Pio L, Musleh L, Paraboschi I, Pistorio A, Mantica G, Clermidi P, et al. Learning curve for robotic surgery in children: a systematic review of outcomes and fellowship programs. J Robot Surg. (2020) 14:53141. doi: 10.1007/s11701-019-01026-w

145. Cundy TP, Rowland SP, Gattas NE, White AD, Najmaldin AS. The learning curve of robot-assisted laparoscopic fundoplication in children: a prospective evaluation and CUSUM analysis. Int J Med Robot. (2015) 11:141-9. doi: 10.1002/rcs.1610

146. Elder JS, Peters CA, Arant BS, Jr., Ewalt DH, Hawtrey CE, Hurwitz RS, et al. Pediatric vesicoureteral reflux guidelines panel summary report on the management of primary vesicoureteral reflux in children. $J$ Urol. (1997) 157:1846-51.

147. Stenberg A, Hensle TW, Läckgren G. Vesicoureteral reflux: a new treatment algorithm. Curr Urol Rep. (2002) 3:107-14. doi: 10.1007/s11934-002-0020-9

148. Subcommittee on Urinary Tract Infection, Steering Committee on Quality Improvement Management, Roberts KB. Urinary tract infection: clinical practice guideline for the diagnosis and management of the initial UTI in febrile infants and children 2 to 24 months. Pediatrics. (2011) 128:595610. doi: 10.1542/peds.2011-1330

149. Subcommittee On Urinary Tract Infection. Reaffirmation of AAP clinical practice guideline: the diagnosis and management of the initial urinary tract infection in febrile infants and young children 2-24 months of age. Pediatrics. (2016) 138:e20163026. doi: 10.1542/peds.2016-3026

150. National Institute for Health and Care Excellence: Urinary Tract Infection in Children: Diagnosis, Treatment and Long-Term Management. Available online at: https://www.nice.org.uk/guidance/cg54/evidence/full-guidelinepdf-196566877 (accessed March, 2021).

151. Cooper CS. Diagnosis and management of vesicoureteral reflux in children. Nat Rev Urol. (2009) 6:481-9. doi: 10.1038/nrurol. 2009.150

Conflict of Interest: GL: speaker at teaching courses for Ferring AB, Sweden; Medical adviser and speaker at instructional courses for Palette AB, Sweden. CC: consultant for Palette Life Sciences, Santa Barbara, CA USA. AK: speaker, consultant, and course director of instructional seminars for Palette Life Sciences.

The remaining author declares that the research was conducted in the absence of any commercial or financial relationships that could be construed as a potential conflict of interest.

Copyright $\odot 2021$ Läckgren, Cooper, Neveus and Kirsch. This is an open-access article distributed under the terms of the Creative Commons Attribution License (CC $B Y)$. The use, distribution or reproduction in other forums is permitted, provided the original author(s) and the copyright owner(s) are credited and that the original publication in this journal is cited, in accordance with accepted academic practice. No use, distribution or reproduction is permitted which does not comply with these terms. 